\author{
Anish Chandra Pandey, B.P. Murty* and R.R. Das** \\ Deptt. PG Studies \& Res. in Chemistry, Govt. SLP PG College (Jiwaji Univ.), Gwalior- 474006 (MP), India \\ * School of Environmental Sciences, JNU, New Delhi - 67/ \\ ** Jiwaji University, Gwalior and Shri RS International University, Raipur. \\ dracpandey@yahoo.co.in; dranishpandey@rediffmail.com
}

\begin{abstract}
This study aims at comparative diffusion/ dispersal capacities, seasonal and diurnal pollution potential (i.e., to explain the ability of the atmosphere to stagnate or dilute pollutants) of some industrial areas of Chhattisgarh in India. For this purpose, the meteorological data of two stations viz. Raipur and Korba have been analyzed for the period of five years (1998 -2002) which included four seasonal representative months: winter (January), pre-monsoon (April), monsoon (July) and post-monsoon (October). The analysis shows absence of stable conditions in the daytime and unstable condition in the night in each seasonal representative month. In general, highest mixing height and ventilation coefficient was recorded during April. From the results it has been concluded that daytime is suitable for good dispersion in all the months. The results also suggest that pollutants are well dispersed in April and July. The vertical dispersion of pollutants / contaminants can peak during January and October. As the predominant winds are northerly or northwesterly, any industrial set up should be in the leeward side i.e. in the southerly or southeasterly of the city in order to minimize the effect of pollutants. This study indicates more conducive atmosphere around Raipur.
\end{abstract}

Keywords: Chhattisgarh. meteorological parameters, pollution, wind roses, ventilation coefficient, emission schedule.

Introduction

Raipur, situated in the central part of Chhattisgarh, lies between latitude $19057 / \mathrm{N}$ to $21053 / \mathrm{N}$ and longitude 81 o 25/ $\mathrm{E}$ to 83038 / $\mathrm{E}$ and at an altitude of $298 \mathrm{~m}$ a.m.s.l. is the capital town of newly found state - Chhattisgarh (carved out of India's largest state Madhya Pradesh and born on November 1, 2000). Chattisgarh is a mineral rich, land locked state enveloped by Maharashtra, Andhra Pradesh, Orissa, Bihar, Uttar Pradesh and of course Madhya Pradesh. Chhattisgarh musters very high agricultural productivity and hence known as the "rice bowl of India". However, it is also facing critical environmental threat. Surrounded by Balaghat, Durg, Jagadalpur, Raigarh, Raipur is an industrial - commercial cum residential area contains the deposits of diamond with sandy type of soil. Korba (latitude $22046 / \mathrm{N}$ and longitude 810 54/ $\mathrm{E}$ and altitude above $625 \mathrm{~m}$ a.m.s.l.), well known for location of Bharat Aluminum Company (BALCO) and National Thermal Power Corporation (NTPC), situated in the northern part of Chhattisgarh, is mainly an industrial area with calcareous type of soil.

The pollution levels at any place and time represent balance between the rates of emission from their sources and the rate at which they are removed from the atmosphere (Wark \& Warner, 1976). For a particular region, temporal variation of pollution depends upon the rate of emissions and the existing meteorological conditions. The assimilative capacity of the atmosphere determines the dilution and dispersion of the pollutants. Air pollution climatology explains the ability of the atmosphere to dilute or stagnate pollutants over a region at any time. Important applications of air pollution climatology are urban planning, industrial location in relation to sensitive areas and air quality management. The different parameters involved in this type of study are the temporal and spatial variation of wind, stability, inversion, mixing height, ventilation coefficient etc. This study aims to analyze the role of climatological factors in the dispersal or diffusion of air pollutants released in to the atmosphere of Raipur and Korba in order to assist in industrial zoning as well as city/ state or country industrial planning.

Materials and methods

The meteorological data of Raipur and Korba for four representative months corresponding to seasons viz. winter (January), pre monsoon (April), monsoon (July) and post monsoon (October) for five years period (1998-2002) have been used. Daily radiosonde data (upper air) of two stations viz. Raipur and Korba (Pendra) for the period 1985-89 (Jan., Apr., July., Oct.) for the levels from surface to $700 \mathrm{mb}$ at $00 \mathrm{GMT}$ has been analysed for upper air wind roses, inversions, mixing heights and ventilation coefficients.

Results and discussion

\section{Study of winds}

The seasonal wind roses (at 03GMT and 12GMT) for Raipur and Korba are presented in Fig. $1 \& 2$. The frequencies of occurrence of calm 
Indian Journal of Science and Technology

Fig. 1. Surface - wind roses for Raipur

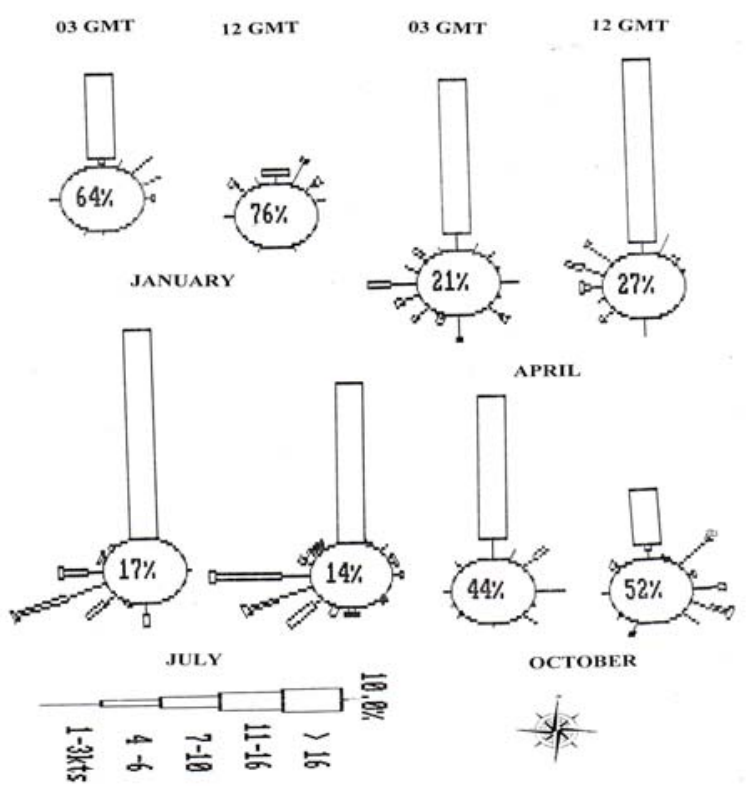

Fig. 2. Surface - wind roses for Korba

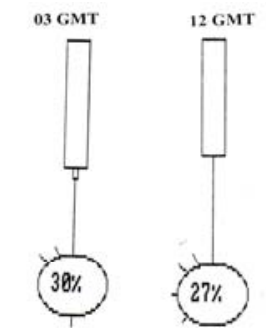

JANUARY

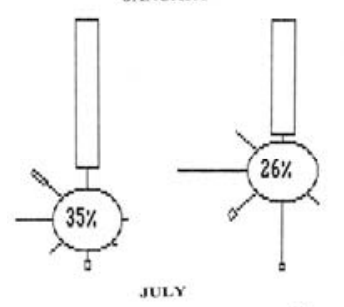

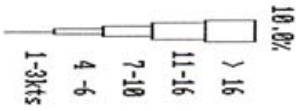

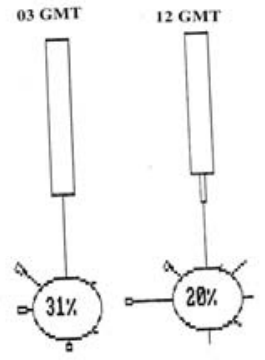

APRIL

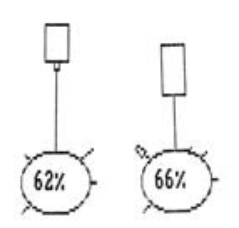

OCTOBER

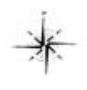

periods were higher at Raipur than Korba for the entire representative months. Out of the four representative months, highest calm periods are $76 \%$ in January and $52 \%$ in October at Raipur and highest (66\%) in October at Korba. Calm/weak winds increase the concentration of pollutants at ground level whereas stronger winds carry the pollutants far away from the source and dilute them (Munn, 1970; 1976). It has been inferred that the occurrence of calm winds in the evening can accumulate and stagnate the pollutants leading to increased ground level concentrations deteriorating http://www.indjst.org

Vol.1 No 5 (Oct. 2008)

the air quality. Due to calm/weak winds, poor carrying capacity of the atmosphere is expected in post monsoon followed by winter season whereas better in summer followed by monsoon season with strong winds. Based on the predominant wind, it is therefore, suggested that the industrial set up should be encouraged in the down wind direction of the cities/urban agglomerations at any place in the studied regions of Chhattisgarh. The predominant winds are northerly N, NW and WSW. Hence, any new industrial set up should be in the down wind of the city (i.e. South /South east of city) in order to minimize the effects of pollutants.

Thus, better dilution of the pollutants leading to reduction in the ground level concentration is expected at Korba compared to Raipur due to stronger winds. Better carrying capacity is expected in pre-monsoon followed by monsoon

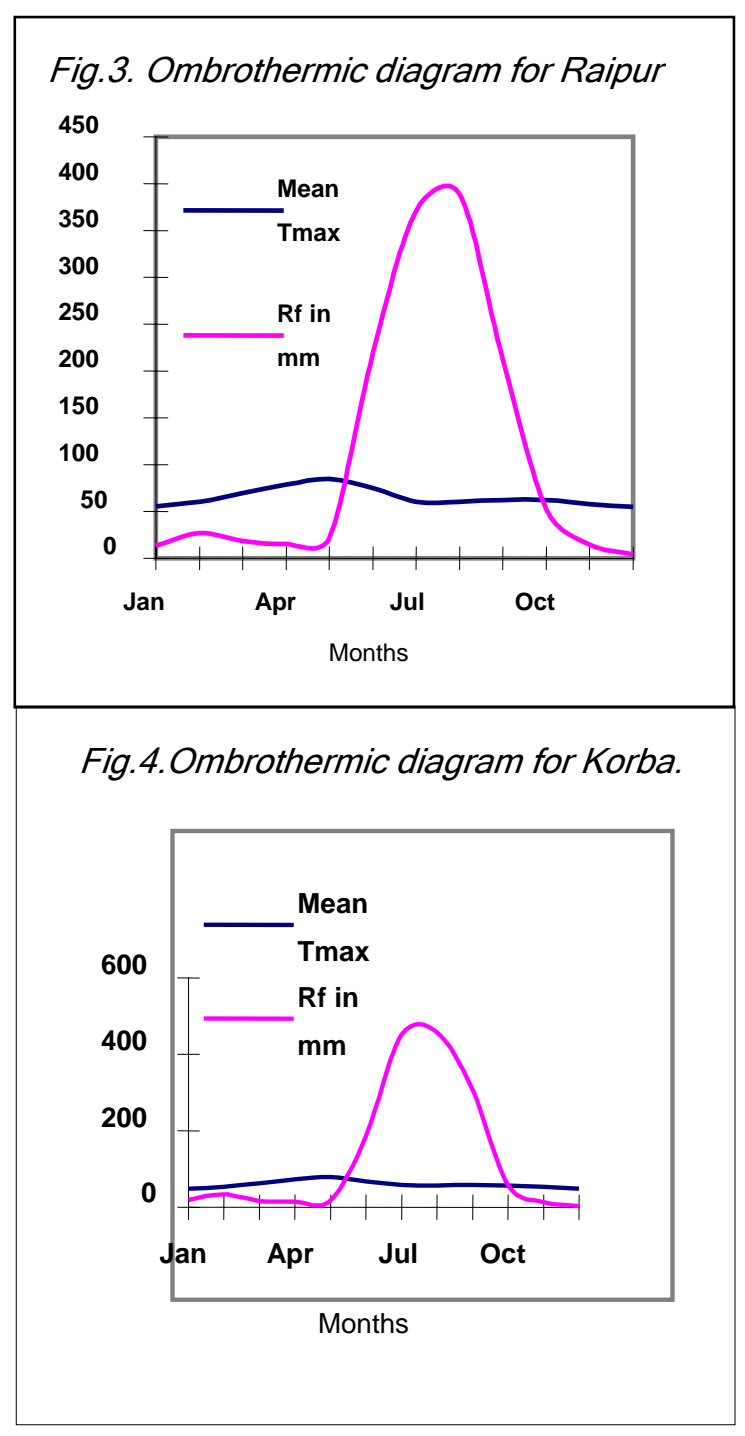


Indian Journal of Science and Technology

http://www.indjst.org

Vol.1 No 5 (Oct. 2008)

and poor carrying capacity exists in winter followed by post-monsoon at both the stations.

if the rain curve falls short to that of temperature the month is to be dry. The present investigations

\begin{tabular}{|l|l|l|l|l|l|l|l|l|}
\hline \multicolumn{1}{|c|}{ Table 1. Pasquill Stabilities at Raipur (Turner, 1964) } \\
\hline & \multicolumn{7}{c|}{ \% Frequency } \\
\hline Month & \multicolumn{1}{|c|}{ Day } \\
\hline & A & B & C & D & D & E & F & G \\
\hline January & 9.8 & 18.2 & 17.5 & 5.2 & 1.8 & 0.6 & 9.9 & 36.8 \\
\hline April & 10.4 & 14.4 & 12.3 & 14.0 & 2.8 & 3.9 & 12.4 & 31.7 \\
\hline July & 0.9 & 4.8 & 17.5 & 27.1 & 21.2 & 4.9 & 20.7 & 3.2 \\
\hline October & 10.4 & 16.7 & 14.4 & 9.7 & 5.8 & 0.8 & 12.3 & 31.8 \\
\hline
\end{tabular}

Table 2. Pasquill Stabilities at Korba (Turner, 1964)

\begin{tabular}{|c|c|c|c|c|c|c|c|c|}
\hline & \multicolumn{1}{|c|}{ \% Frequency } \\
\hline Month & \multicolumn{3}{|c|}{ Day } & \multicolumn{4}{c|}{ Night } \\
\hline & $\mathrm{A}$ & $\mathrm{B}$ & $\mathrm{C}$ & $\mathrm{D}$ & $\mathrm{D}$ & $\mathrm{E}$ & $\mathrm{F}$ & $\mathrm{G}$ \\
\hline January & 19.5 & 4.8 & 14.9 & 12.7 & 0.8 & 1.7 & 7.8 & 37.5 \\
\hline April & 5.9 & 15.9 & 14.5 & 13.4 & 4.7 & 7.5 & 12.7 & 25.7 \\
\hline July & 0.8 & 7.8 & 8.0 & 32.5 & 12.2 & 9.1 & 21.4 & 7.5 \\
\hline October & 11.4 & 6.7 & 15.1 & 16.7 & 2.8 & 1.4 & 10.2 & 35.6 \\
\hline
\end{tabular}

A-Extremely unstable, B-Moderately unstable, C-Slightly

unstable, D-Neutral, E-Slightly stable, F-Moderately stable,

\section{Study of Omborthermic diagrams}

G-Extremely stable.

To assess pollution removal efficiency of Raipur and Korba, Ombrothermic diagrams are presented in Fig. $3 \& 4$ respectively. It indicates that at both the stations there is one wet phase falling between June to September. There are two dry phases, one falling when the mean temperature is high and the other when it is low. Thus there is a dry winter extending from November to January and a dry summer extending from March to May. February and October months represent the period of transition from winter to summer and rainy to winter respectively. At both Raipur and Korba, the peak of rainfall is during August and then it falls gradually. The highest temperature prevails during May. Peak rainfall for Korba is recorded in August and peak temperature in May.

As per the climatic classifications, when the curve of rainfall exceeds that of the temperature, the month is supposed to be wet. On the contrary,

Table 3. \% Frequencies of Ground Inversions at Raipur and Korba.

\begin{tabular}{|c|c|c|c|c|c|}
\hline STATION & $\begin{array}{c}\text { TIME } \\
\text { (GMT) }\end{array}$ & \multicolumn{4}{|c|}{ SEASONAL MONTHS } \\
\hline & & JAN & APR & JUL & OCT \\
\hline RAIPUR & 00 GMT & 71 & 48 & 08 & 41 \\
\hline & 12 GMT & 08 & 05 & 04 & 05 \\
\hline KORBA & 00 GMT & 84 & 58 & 18 & 52 \\
\hline & 12 GMT & 09 & 04 & 02 & 07 \\
\hline
\end{tabular}

indicate that the dry phase extends from October to June and the wet phase is a short lived one extending from July to September. Relative variation of temperature-precipitation curve could be used to assess the efficiency of sink mechanism in the atmosphere. For example, if the precipitation curve continues to exceed the temperature curve, wet processes like mist/fog/aerosol formation are favoured in the beginning. As season advances, the precipitation may wash out the pollutants from the atmosphere. During other periods, the high temperature versus little rainfall favours for dry processes viz. entrainment of particulate matter into the atmosphere and dominance of impact of pollutants on surface. Hence, it can be concluded that at those stations where rainfall curve is high over temperature, pollutant levels are brought down by natural processes (wet mechanism) compared to dry areas. Fig. $3 \& 4$ shows that rainfall curve to temperature are higher for all the station from mid June to September. Hence, wet removal of pollutants will be more effective in monsoon for all the stations. Based on the above criteria, Korba will show least effective wet removal or wash out of pollutants in the monsoon and most effective at Raipur.

\section{Study of stabilities}

Pasquill stability classes were determined by the use of Turner's (1964) and Holzworth (1974) methods for Raipur and Korba. The frequencies of occurrence of all stability classes are also given in Table 1 for Raipur and Table 2 for Korba separately for day and night periods.

The above atmospheric stability classification is based on latitude, cloudiness and wind speed. In this classification extreme instability is associated with maximum dispersion of pollutants. Inhibition of turbulence associated with inversions and calm periods leads to stable atmosphere causing minimum diffusion of pollutants i.e., stagnation of pollutants. Neutral atmosphere is the intermediate stage between these two that may move towards instability on one side and the stability on the other.

No unstable conditions have been observed during night time and stable conditions during day time at either of the stations in all the four representative months of the season. The present results are in good agreement with that of Hosler 
(1961), Sadhuram and Vittalmurty (1986) and Padmanabhamurty and Tangirala (1988), Panday et al. (2005). The neutral stability "D" has occurred both during day and night but its frequency was less during night for both the stations in all the months. Generally, there are only four classes Extremely unstable (A), Moderately unstable (B), Slightly unstable (C) and Neutral (D) for day time and four classes - Neutral (D), Slightly stable (E), Moderately stable $(F)$ and Extremely stable $(G)$ for night. Frequencies of stability classes "F" and "G" have higher values than " $D$ " and " $E$ " at both the stations in the nighttime except in July in which "D" has highest value for Raipur. Except in the month of April (i.e., Summer), Raipur experiences more frequencies of "G" stability than Korba. Thus, it can be concluded form the present study that dispersion capacity at Korba is higher than at Raipur, because of comparatively more unstable conditions at Korba. Better dispersal of pollutants during the day time can be expected especially in summer (April) and monsoon (July), whereas, poor dispersion is expected at night particularly in winter (January) and post monsoon (October).

It has been observed that inversion and stable conditions occurred more frequently in the morning and less frequently in the evening in all the seasonal representative months and for both the stations. Due to the increase of solar radiation and air temperature the stable condition of atmosphere in the morning may change into unstable condition in daytime, which increases the turbulence by destroying the lapse rate of the atmosphere. The case is vice-versa for the evening and night. According to Ogawa et al. (1985) the turbulence intensity decreases as the stability of the atmosphere changes from unstable to stable condition. Based on these considerations it may be concluded that turbulence intensity in the daytime is expected to decrease slowly in January (Winter) and rapidly in July (Monsoon) followed by April (Pre-monsoon). Per cent frequencies of calm periods at Korba were higher than Raipur.

It is generally
observed that no
definite direction is
associated with any stability; however winds are comparatively stronger during unstable conditions. It can therefore be concluded that better diffusion conditions exist in April and July and also during daytime in all the months under both unstable and neutral conditions. Highest Calm periods were observed for Korba than Raipur in January and April while vice-versa in July and October for stable conditions.

\section{Study of inversions}

Percentage frequencies of ground inversions (Table 3) and ground-based inversions with various top heights have been computed and discussed for Raipur and Korba at 00 and 12 GMT. The atmosphere within the planetary boundary layer $(1.5 \mathrm{~km})$ has been considered for the study of percentage frequency distribution of inversions. The frequencies have been rounded to nearest whole number. Frequencies of inversions over Raipur and Korba show large variations in the morning and less in the evening hours. At 00GMT at Raipur generally the ground-based inversions were restricted to 900 - 1000. At 12 GMT never they exceed $501-600 \mathrm{~m}$. At Raipur however the ground based inversions extended up to 14011500 at 00GMT. But at 12 GMT they were restricted again to 501-600m.At 00GMT, highest frequencies of inversions have been observed at Raipur in the month of January $(71 \%)$ followed by April (48\%). The month of July (8\%) showed extremely low frequency. It has increased again in October (42\%). At $00 \mathrm{GMT}$, highest frequencies of inversion layers have been shown by Korba in the month of January (84\%) followed by April (58\%) whereas extremely low frequency was found in the month of July (18\%). It showed increasing trend again in the month of October (52\%).

At $12 \mathrm{GMT}$, the frequencies of inversions found at Raipur was $8 \%$ in January, $5 \%$ in April, $4 \%$ in July and $05 \%$ in October whereas at 12 GMT, the frequencies of inversions at Korba were $9 \%$ in January, $4 \%$ in April, $2 \%$ in July and $7 \%$ in October.

The frequency of inversion was the maximum
Table 4. Diurnal Variation of Mean Ventilation Coefficients (m2s-1) at Raipur

\begin{tabular}{|c|c|c|c|c|c|c|c|c|}
\hline SEASONITIME & 00 & 03 & 06 & 09 & 12 & 15 & 18 & 21 \\
\hline Winter & 370 & 618 & 2876 & 5452 & 5122 & 1252 & 734 & 678 \\
\hline Pre monsoon & 1064 & 3278 & 5532 & 14565 & 13054 & 8974 & 2997 & 1496 \\
\hline Monsoon & 1054 & 1934 & 4670 & 4782 & 4780 & 4224 & 2126 & 1564 \\
\hline Post monsoon & 448 & 945 & 2426 & 4896 & 4567 & 2190 & 1190 & 658 \\
\hline
\end{tabular}

Table 5. Diurnal Variation of Mean Ventilation Coefficients (m2s-1) at Korba

\begin{tabular}{|c|c|c|c|c|c|c|c|c|}
\hline SEASONITIME & 00 & 03 & 06 & 09 & 12 & 15 & 18 & 21 \\
\hline Winter & 329 & 589 & 2782 & 5491 & 5056 & 1345 & 786 & 590 \\
\hline Pre monsoon & 1109 & 3341 & 5599 & 12996 & 14044 & 9038 & 3068 & 1279 \\
\hline Monsoon & 997 & 1886 & 4642 & 4824 & 4821 & 4279 & 2046 & 1634 \\
\hline Post monsoon & 414 & 976 & 2418 & 4908 & 4588 & 2226 & 1086 & 477 \\
\hline
\end{tabular}


in January at both the stations i.e., Raipur and Korba at 03 and 12 GMT. The frequency of inversion at $03 \mathrm{GMT}$ was much higher than that at 12 GMT. This may be due to the occurrence of mostly lapse conditions caused by intense surface heating at 12 GMT compared to that at 03 GMT.

It has been reported by Katsoulis (1988) that these inversions develop frequently during nighttime (for almost half of the nights), and rapidly erode during the day. In July, the minimum frequency of inversions is due to cloudy weather and strong winds.

\section{Fig. 5 (a) Seasonal mean mixing height}

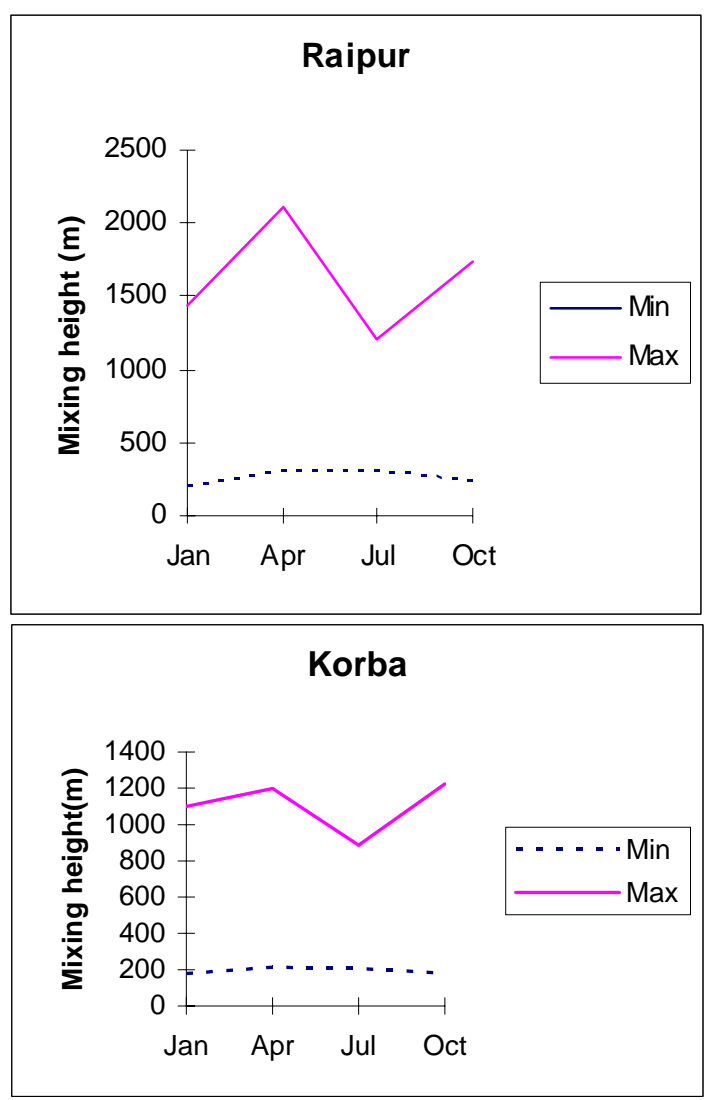

Ground based inversions restrict the dispersion of pollutants vertically within it. The top inversions act as a lid and restricts effectively the dispersal of pollutants released below it and the inversions are thus responsible to affect the ambient air quality. Considering the role of inversions above, it can be concluded that among all the months, January (Winter) may be the worst month for mixing of pollutants whereas, July (Monsoon) is the better month for dispersion in the study area. This observation is in conformity with the observation made by Rai and Padmanabhamurty (1993) for
Patna (Bihar) and Pandey and Padmnabhamrty (2005) for Bhopal (Madhya Pradesh). A comparative study has been made for inversions at Raipur and Korba shows that better mixing of pollutants is expected at Raipur than Korba.

\section{Mixing height}

Hourly mean mixing heights during the day period have been calculated as per Holzworth's (1967) method for five years (1985 to 1989) at Raipur and Korba for all representative months of the seasons i.e., January, April, July and October reveals that:

In January, the mean minimum mixing height 258 meters was observed at 00GMT and the mean maximum mixing height at 1452 meters at 09GMT for Raipur, where as for Korba, the mean mixing height was found at 188 meters at 00GMT and mean maximum mixing height at 1379 meters at 09GMT. In April, the mean minimum mixing height was calculated to be 299 meters and mean maximum mixing height at 2116 meters for Raipur at 00GMT and 09GMT respectively whereas, for Korba it was observed at 326 meters and at 2089 meters.

At Raipur, the mean mixing height both minimum and maximum was between 304 meters to 1199 meters in July whereas; at Korba it was between 217 to 1215 meters. In July, the difference between mean maximum and mean minimum mixing height was found to be minimum in comparison to other months. The minimum variation in July at both the stations was due to overcast conditions which caused less mixing during the day because of the relatively low surface temperature but greater mixing at night because of the relatively high surface temperature. At Raipur the mean mixing height both minimum and maximum ranged between 228 meters to 1742 meters in October. Mean minimum mixing height was calculated to be 240 meters and maximum 1690 meters at Korba.

Both at Raipur and Korba, the minimum mixing height was observed at 00GMT. The maximum mixing height was observed mostly at 09 GMT except in July, which observed it at 12 GMT. The mixing height increased from 00 GMT to 12 GMT and thereafter it decreased. This was due to the diurnal variation of surface temperature. In all cases, values were minimum during the early morning hours and maximum during afternoon. Calm winds prevail during nights result in greater loss of ground radiation in absence of the heat source. The nighttime mixing heights were lower compared to the afternoon mixing heights. 
Fig. 5 (b) Seasonal mean wind speed through the mixing layer
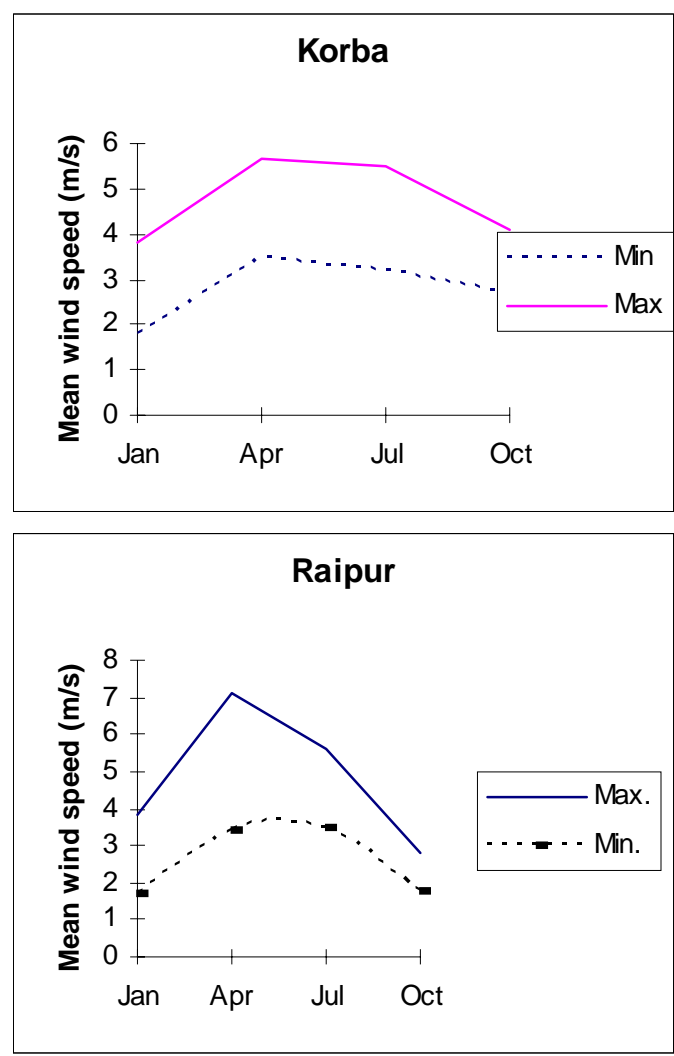

Among the four seasonal representative months, the highest mixing height occurred in April followed by October, January and July. In April, the highest mixing height values may be due to the maximum surface heating. The percentage frequencies of occurrence of low mixing heights were the maximum in winter due to the presence of surface based inversion. In other seasons, higher mixing heights were observed during summer (in April). It may be due to the fact that the amount of incoming solar radiation is higher during this season and as the soil is dry, this radiation is preferably converted into sensible than latent heat flux and turbulence, favoring the development of a deep mixing layer. Contrary to this, the amount of incoming solar radiation is less and as the soil is moist and covered with vegetation, most of this radiation is converted into latent heat; thus the vertical development of the mixing layer is reduced during winter. The observed mixing height in the afternoon is deeper during the transient period than in winter due to the fact that the soil is warmer and the amount of incoming solar radiation is greater. The results of the present study are in good agreement with those of seasonal variation of mixing height in Delhi (Murty \& Tangirala, 1990).

Due to the highest mixing height in April among all the seasons, good vertical mixing of contaminants may take place in this month especially during afternoon. In July, pollutants will be removed by wet deposition (i.e., Rainout and Washout) and their concentration will be relatively lower though the mixing heights are low. January and October may be regarded as the worst months for diffusion or vertical mixing of contaminants. In general, Raipur has higher mixing heights compared to Korba.

\section{Ventilation coefficient}

Ventilation coefficient is the product of mixing height and average wind speed within the mixing layer. Winds used in these calculations were the averages over the entire mixing layer. The average wind speed through the mixing layer was calculated as a simple average of the wind speed aloft (up to mixing height) as determined by radio wind data of wind speed and surface wind speed. Monthly mean ventilation coefficients for five years have been calculated for 00, 03, 06, 09, 12, 15, 18 and 21 GMT for all the representative months at Raipur and Korba are presented in Tables 4 and 5. It was calculated by multiplying mean wind speed within the mixing layer with mixing heights. In January, the mean minimum and mean maximum ventilation coefficients were ranged between 370 and $5452 \mathrm{~m} 2 \mathrm{~s}-1$ at Raipur. The maximum ventilation coefficient occurred mostly at 09 GMT and the minimum ventilation coefficient at $00 \mathrm{GMT}$. The mean minimum and maximum ventilation coefficient ranges between 329 and 4590 m2s-1 at Korba.

In April, the mean minimum and maximum ventilation coefficients ranged from 1064 to 14565 m2s-1 at Raipur. The maximum ventilation coefficients were found normally at 09 GMT and the minimum at $00 \mathrm{GMT}$ for all the studied years. The mean ventilation coefficients ranged from 1109 to 12994 m2s-1 at Korba. In July, the mean minimum and maximum ventilation coefficients ranged between 1054 and 4782 m2s-1 at Raipur. The mean ventilation coefficients ranged from 997 to $4824 \mathrm{~m} 2 \mathrm{~s}-1$ at Korba. At 12GMT in July, the maximum mean ventilation coefficient was found at 12 GMT whereas minimum ventilation coefficient was observed at $00 \mathrm{GMT}$. In October at Raipur, the mean minimum and maximum ventilation coefficients ranged from $448 \mathrm{~m} 2 \mathrm{~s}-1$ to $4896 \mathrm{~m} 2 \mathrm{~s}-1$. The mean ventilation coefficients ranged from 414 m2s-1 to 4908 m2s-1 at Korba. The maximum 
ventilation coefficient was observed at 09 GMT and the minimum at $00 \mathrm{GMT}$.

Fig. 5 (c). Seasonal mean ventilation coefficients
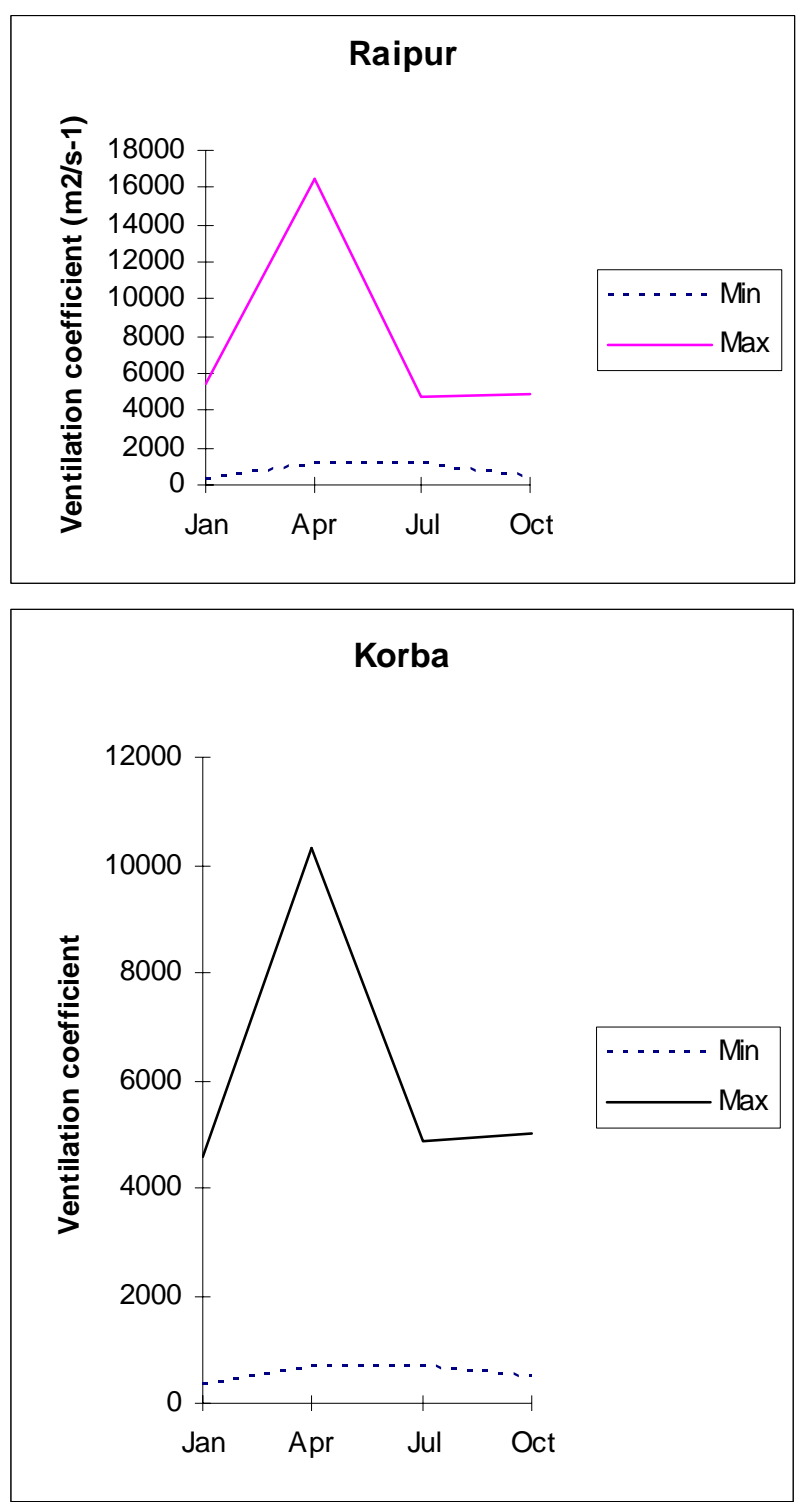

Ventilation coefficient is an important parameter for assessing high pollution potential. It is a parameter that indicates the capacity or efficiency of the atmosphere in dispersing air pollutants released from local sources. Low ventilation coefficients indicate poor dispersion capacity of the atmosphere for air pollutants. Based on the analysis of observations it can be concluded that April has the highest maximum ventilation coefficient (in the afternoon) and July has the lowest maximum ventilation coefficient. The mean afternoon ventilation coefficient is nearly the same in July and October. Higher values of ventilation coefficient were mainly due to the very high mixing heights during the daytime whereas ventilation coefficients were small during night due to low mixing height and light prevailing winds. Highest mean maximum values of ventilation coefficients were found mostly at 09 and 12 GMT whereas mean minimum were observed at 00 and 03 GMT.

\section{Pollution potential}

Gross (1970) criteria for assessing/forecasting pollution potential is widely used by US National Meteorological Center and Atmospheric Environment Service Canada. The Gross (1970) criteria for assessing high pollution potential are that the morning mixing depths should be $\leq 500$ meters and transport wind speed $\leq 4$ meter/sec and afternoon's ventilation coefficient $\leq 6000$ $\mathrm{m} 2 / \mathrm{Sec}$ and transport wind speed $\leq 4 \mathrm{~meter} / \mathrm{sec}$. Due to the unavailability of any standard criteria for assessing high pollution potential in India an attempt has been made in the present study to delineate periods of high pollution potential at Raipur and Korba applying the above criteria.

The mean monthly morning (minimum) and afternoon (maximum) mixing heights and average transport wind through the mixing layer and morning (minimum) and afternoon (maximum) ventilation coefficients for four representative months viz., January (Winter), April (Premonsoon), July (Monsoon) and October (Post monsoon) at Raipur and Korba have been presented in Fig. 5 (a-c).

In the present study it was found that morning periods have high pollution potential in all the seasons which decreases gradually during the day and eventually disappeared in the afternoon at both the stations applying Gross (1970) criteria of forecasting high pollution potential. It was also observed that afternoon periods have low pollution potential in the month of April and July at Raipur and in the month of April, July and October at Raipur. Better dispersion of pollutants is also expected in summer (April) season due to higher mixing heights and ventilation coefficients and poor in winter (January) followed by post-monsoon (October) season due to lower mixing heights and ventilation coefficients. The afternoons of April are expected to be better periods for vertical mixing of contaminants. The pollutants will be removed through wet deposition in the month of July and their concentration will be lower even though mixing height and ventilation coefficient are low. The results show that the pollutants will be well dispersed in the months of April and July. The months of January and October might be regarded 
Indian Journal of Science and Technology

as the worst months for dispersal/diffusion of contaminants at both Raipur and Korba.

\section{Conclusion}

The predominant winds were $\mathrm{N}$ and NW. Low winds were observed in January and October and high in April and July for both the stations. The dilution of pollutants is expected in April and accumulation in January. From the wind direction, it can be concluded that no major polluting industry can be set up in the $S$ and SE sector of the capital region of Chattisgarh (Raipur). Among four representative months, good dispersal of pollutants takes place in April and July where as poor dispersal/ diffusion in January and October and nighttime of all the months. Of all four months Raipur shows highest frequencies of inversion layers in January and lowest in July. Hence January is the month favouring for highest mixing of pollutants whereas July is moderate.

Among the four months, the highest afternoon mixing height and ventilation coefficient occurred in April. Morning hours had a high pollution potential which decreases gradually with the time of day. Thus, it can be concluded from this study that premonsoon (April) and monsoon (July) months have a high carrying capacity of pollutants. Winter (January) and post monsoon (October) months have less dispersal capacity. Night and early morning hours have less dispersal capacity of pollutants due to stable atmosphere accompanied by weak or no winds.

Acknowledgement

Anish Chandra Pandey acknowledges with thanks Indian Meteorological Department, Nagpur and Pune for providing meteorological data of Raipur and Korba.

\section{References}

1. Gross E (1970) The national air pollution potential forecast program. ESSA Tech. Mem. WBTM NMC. 47, U.S. Department of Commerce.

2. Holzworth CG (1974) Climatological aspects of the composition and pollution of the atmosphere. W.M.O., Tech. Note No. 139, W.M.O., Geneva.

3. Hosler CR (1961) Low-level inversion frequency in the composition and pollution of atmosphere. Mon. Wealth. Rev. 89, 319-339.

4. Kallos G, Kassomenos P and Pielke R (1993) Synoptic and mesoscale circulations associated with air pollution episodes in Athens, Greece. Boundary Layer Met. 63, 163-184.

5. Katsoulis, BD (1988) Aspects of occurrences of persistent surface inversions over Athens http://www.indjst.org

Vol.1 No 5 (Oct. 2008)

basin, Greece. Theo. App. Climatology 39, 98-107.

6. Millan MM, Salvador R, Acena B, Bezares JC, Martin M, Pujadas M, Goberna J, Albizuri A and Navazo M (1988) Field measurement of plume dispersion in a complex coastal site. Castellon. In proc. COST 611: Workshop on field measurements and their interpretation, Villefranche Sur Mer, France-4, May 1988.

7. Munn RE (1970) Air pollution meteorology in manual on Urban Air Quality Management. Regional Publications, European Series No. 1, WMO, Copenhagen.

8. Munn RE (1970) Air flow in urban areas, Urban climates. W.M.O. Tech. Note No. 108, 15-39, W.M.O., Geneva, Switzerland.

9. Munn RE and Hirt MS (1976) Recent Canadian trends in air pollution meteorology. Naturaliste Can. 96, 711-724.

10. Ogawa $Y$, Diosey PG, Uehara $K$ and Ueda $H$ (1985) Wind tunnel observation of flow and diffusion under stable stratification. Atmospheric Environment 19, 65-74.

11. Padmanabhamurty B and Tangirala RS (1988) An assessment of the assimilative capacity of the atmosphere at Delhi. International conference on tropical micrometeorology and air pollution, New Delhi.

12. Padmanabhamurty B and Tangirala RS (1990) An assessment of the assimilative capacity of the atmosphere at Delhi. Atmospheric Environment 24 (A), 845-848.

13. Pandey AC, Murty BP and Das RR (2005) Air pollution climatology of Bhopal and Gwalior. Indian J. Air Pollution Control, 5 (2), 24-33.

14. Rai B and Padmanabhamurty B (1993) Dispersion climatology of Patna and Gaya, Mausam 44,199-204.

15. Sadhuram Y and Vittalmurty KPR (1986) Diurnal and seasonal variation of pasquill stability class at coastal station. Mausam 37, 187-192.

16. Turner DB (1964) A diffusion model of an urban area. J. Appl. Meteorology 3, 83-91.

17. Wark K and Warner CF (1976) Air pollution, its origin and control. IEP A Dun Donnellyey Publishers, New York. 